\title{
Acetazolamide and Inhaled Carbon Dioxide Reduce Periodic Breathing During Exercise in Patients With Chronic Heart Failure
}

\author{
ANNA APOSTOLO, MD,${ }^{1}$ PIERGIUSEPPE AGOSTONI, MD, PhD,${ }^{1,2}$ MAURO CONTINI, MD,${ }^{1}$ LAURA ANTONIOLI, MD,${ }^{1}$ AND \\ ERIK R. SWENSON, MD ${ }^{3}$ \\ Milan, Italy; Seattle, Washington
}

\begin{abstract}
Background: Periodic breathing (PB) during sleep and exercise in heart failure (HF) is related to respiratory acid-base status, $\mathrm{CO}_{2}$ chemosensitivity, and temporal dynamics of $\mathrm{CO}_{2}$ and $\mathrm{O}_{2}$ sensing. We studied inhaled $\mathrm{CO}_{2}$ and acetazolamide to alter these factors and reduce PB.

Methods and Results: We measured expired and arterial gases and PB amplitude and duration in $20 \mathrm{HF}$ patients during exercise before and after acetazolamide given acutely (500 mg intravenously) and prolonged ( 24 hours, $2 \mathrm{~g}$ orally), and we performed overnight polysomnography. We studied $\mathrm{CO}_{2}$ inhalation $(1 \%-2 \%)$ during constant workload exercise. PB disappeared in $19 / 20$ and $2 / 7$ patients during $2 \%$ and $1 \%$ $\mathrm{CO}_{2}$. No changes in cardiorespiratory parameters were observed after acute acetazolamide. With prolonged acetazolamide at rest: ventilation $+2.04 \pm 4.0 \mathrm{~L} / \mathrm{min}(P=.001)$, tidal volume $+0.11 \pm 1.13 \mathrm{~L}$ $(P=.003)$, respiratory rate $+1.24 \pm 4.63$ breaths $/ \mathrm{min}(\mathrm{NS})$, end-tidal $\mathrm{PO}_{2}+4.62 \pm 2.43 \mathrm{~mm} \mathrm{Hg}$ $(P=.001)$, and end-tidal $\mathrm{PCO}_{2}-2.59 \pm 9.7 \mathrm{~mm} \mathrm{Hg}(P<.001)$. At maximum exercise: Watts $-10 \%$ $(P<.02), \mathrm{VO}_{2}-61 \pm 109 \mathrm{~mL} / \mathrm{min}(P=.04)$ and $\mathrm{VCO}_{2} 101 \pm 151 \mathrm{~mL} / \mathrm{min}(P<.02)$. Among 20 patients, $\mathrm{PB}$ disappeared in 1 and 7 subjects after acute and prolonged acetazolamide, respectively. PB was present $80 \% \pm 26,65 \% \pm 28$, and $43 \% \pm 39$ of exercise time before and after acute and prolonged acetazolamide, respectively. Overnight apnea/hypopnea index decreased from $30.8 \pm 83.8$ to $21.1 \pm 16.9$ $(P=.003)$.
\end{abstract}

Conclusions: In HF, inhaled $\mathrm{CO}_{2}$ and acetazolamide reduce exercise $\mathrm{PB}$ with additional benefits of acetazolamide on sleep PB. (J Cardiac Fail 2014;20:278-288)

Key Words: Oscillatory ventilation, cardiopulmonary exercise test, polysomnography.

Nocturnal and daytime periodic breathing (PB) in patients with moderate to severe chronic heart failure (HF) is not uncommon and is independently predictive of earlier mortality. ${ }^{1}$ This is true also for PB during exercise or exercise oscillatory ventilation. ${ }^{2}$ The genesis of PB in HF has

From the ${ }^{1}$ Centro Cardiologico Monzino, IRCCS, Milan, Italy; ${ }^{2}$ Department of Clinical Sciences and Community Health, University of Milan, Milan, Italy and ${ }^{3}$ Pulmonary and Critical Care Medicine, Veterans Administration Puget Sound Health Care System, University of Washington, Seattle, Washington.

Manuscript received October 3, 2013; revised manuscript received December 23, 2013; revised manuscript accepted January 7, 2014.

Reprint requests: Piergiuseppe Agostoni, MD, PhD, Centro Cardiologico Monzino, IRCCS, Cardiovascular Section, Dept. of Clinical Sciences and Community Health, University of Milano, via Parea, 4 (20138) Milano, Italy. Tel: +39-2-58002586; Fax: +39-02-58002398. E-mail addresses: piergiuseppe.agostoni@unimi.it or piergiuseppe.agostoni@ ccfm.it

See page 287 for disclosure information.

1071-9164/\$ - see front matter

(c) 2014 Elsevier Inc. All rights reserved.

http://dx.doi.org/10.1016/j.cardfail.2014.01.007 been attributed to a variety of factors, including reduced cardiac output resulting in an increased transit time of blood from the pulmonary vasculature to the central and peripheral chemoreceptors, low lung volume, pulmonary congestion, and augmented peripheral chemoreceptor sensitivity leading to a lower eupneic (baseline) $\mathrm{PaCO}_{2}$ and a narrowing of the difference between the eupneic $\mathrm{PaCO}_{2}$ and the apneic (or hypoventilatory) $\mathrm{PaCO}_{2}$ threshold. ${ }^{3}$ Notably, a central hypothesis for PB genesis has also been proposed. This hypothesis is based on a derangement of the vasomotor rhythm which modulates ventilation either indirectly through blood flow modulation or directly through central irradiation to the respiratory centers. $^{4-6}$

We have previously shown that addition of $250 \mathrm{~mL}$ and $500 \mathrm{~mL}$ of added external dead space reduced PB during exercise in HF patients. This was most evident as the nadir tidal volume $(\mathrm{Vt})$ of each cycle approached the peak $\mathrm{Vt},{ }^{7}$ supportive of the idea that lung volume may be a factor. Yet as a result of the added dead space, end-tidal $\mathrm{PCO}_{2}$ 
$\left(\mathrm{PetCO}_{2}\right)$ rose and we could not rule out suppression of $\mathrm{PB}$ by an increase in the eupneic to apneic $\mathrm{PCO}_{2}$ difference. Others have shown in $\mathrm{HF}$ patients that inspiration of low concentrations of $\mathrm{CO}_{2}(3 \%)$ reduces $\mathrm{PB}$ or Cheyne-Stokes respiration by this same mechanism. ${ }^{8-10} \mathrm{~A}$ third and independent means to possibly alter the eupneic-apneic $\mathrm{PCO}_{2}$ difference favorably is by administration of acetazolamide, a carbonic anhydrase (CA) inhibitor that acts by several mechanisms to reduce $\mathrm{PB}$ during sleep at high altitude ${ }^{11,12}$ and in those with $\mathrm{HF}^{13,14}$ In a small study of 12 patients with HF, Fontana et $\mathrm{al}^{14}$ found that low-dose acetazolamide (250 mg twice a day) for 4 days did not eliminate PB during exercise in the $50 \%$ of patients who displayed the phenomenon, although it was effective in the whole group in reducing the nocturnal and diurnal apnea-hypopnea indexes.

Our aims in the present study were to measure during exercise in HF patients with an acetazolamide dose capable of altering both peripheral and central $\mathrm{CO}_{2}$ chemosensitivity. ${ }^{15}$ To do so, we studied the drug effect after an acute intravenous administration (500 $\mathrm{mg}$ ) and compared it with the response following 3 oral doses over 24 hours (500 mg every 8 hours). The difference in the 2 dosing regimens was to determine whether the suppression of PB by acetazolamide is due to its effects on chemoreceptor and red cell CA inhibition (acute administration) independently from its known stimulant effect on ventilation $\left(\mathrm{V}_{\mathrm{E}}\right)$ arising from the metabolic acidosis of renal $\mathrm{CA}$ inhibition that requires several hours to develop and 12-24 hours to be fully established (prolonged administration). Additionally, we sought to compare the acetazolamide effects with those of low concentrations of inhaled $\mathrm{CO}_{2}(1 \%-2 \%)$ able to generate roughly the same small magnitude of tissue hypercapnia occurring from inhibition of red cell and vascular endothelial cell CA with acetazolamide. ${ }^{12}$

\section{Materials and Methods}

We studied 20 consecutive patients with HF (New York Heart Association [NYHA] functional classification II-III) and PB during exercise. These patients belong to the cohort of our HF clinic, who undergo routine follow-up which includes clinical and laboratory evaluations, echocardiography, spirometry, and cardiopulmonary exercise test (CPET). PB was defined as a cyclic fluctuation of ventilation present at rest and during exercise, with amplitude swings $>30 \%$ of the mean $V_{E},>15 \%$ for $\geq 60 \%$ of incremental exercise duration. ${ }^{16}$ The protocol was approved by our Institutional Ethics Committee (ClinTrials.gov NCT00517426), and written informed consent was obtained from each patient.

Study inclusion criteria were evidence of HF in stable clinical conditions, LVEF $<40 \%$, PB during exercise, and age 18-80 years. Study exclusion criteria were presence of unstable angina, NYHA functional class IV, recent ( $<6 \mathrm{mo}$ ) myocardial infarction, severe valvular disease, severe obstructive or restrictive lung disease (1-second forced expiratory volume or functional vital capacity $<60 \%$ of predicted value), symptomatic peripheral vascular disease or orthopedic problems that could limit exercise

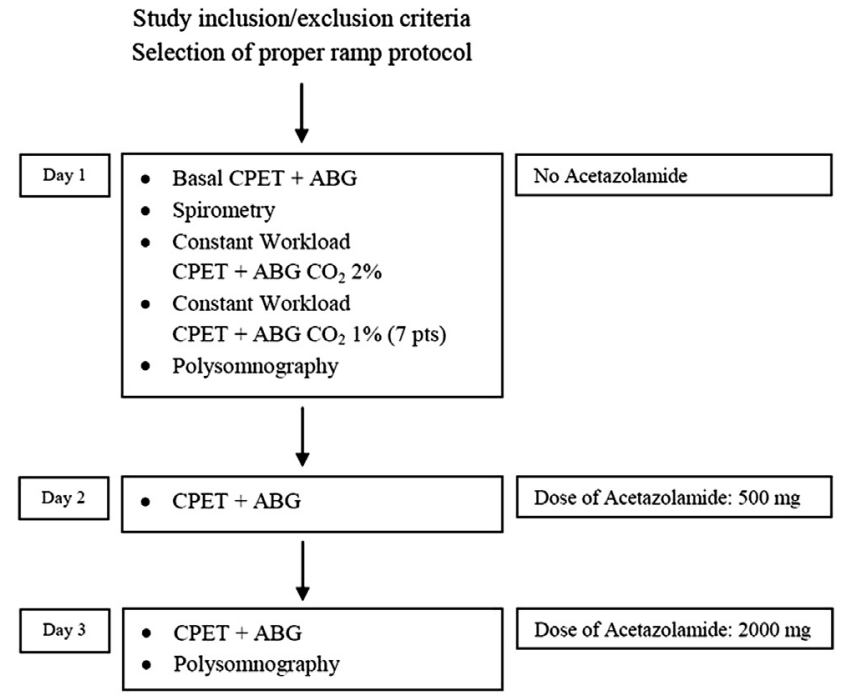

Fig. 1. Flow-chart of the tests performed. CPET, cardiopulmonary exercise test; $\mathrm{ABG}$, arterial blood gas test.

performance, and neurologic diseases, such as dementia, stroke, or cerebrovascular disease.

To select patients for this study, we performed the following tests in patients regularly followed in our HF clinic: cardiac ultrasound evaluation to determine left ventricular volume and ejection fraction (LVEF), standard spirometry to exclude severe lung disease, and maximal ramp (5-10 W/min) symptom-limited CPET for familiarization purposes and to select patients with $\mathrm{PB}$ during exercise. During the CPET performed with a cycle ergometer, patients breathed through a mouthpiece connected to a mass flowmeter. We used a personalized ramp protocol aimed at achieving a maximal effort in $\sim 10$ minutes. If this was not obtained, the ramp protocol was adjusted accordingly in a 2 nd test to achieve a 10-minute duration. The loaded exercise was preceded by a few minutes $(>5 \mathrm{~min}$ ) of resting ventilation measurements and by a $>3$-minute period of unloaded pedaling. $\mathrm{V}_{\mathrm{E}}$, oxygen consumption $\left(\mathrm{VO}_{2}\right)$, and carbon dioxide production $\left(\mathrm{VCO}_{2} ; \mathrm{V}\right.$-max; Sensormedics, Yorba Linda, California) were measured breath by breath. A 12-lead electrocardiogram was recorded continuously to derive heart rate and monitor for ischemic or ectopic changes. During exercise, arterial pressure was measured every 2 minutes by sphygmomanometer. All patients meeting the inclusion/exclusion criteria underwent 3 days of testing. Figure 1 is a consort diagram of the experimental protocol.

\section{Day 1}

On the 1st study day, patients performed a ramp CPET (as defined above) with arterial blood gas samples taken at rest and every 2 minutes during exercise via a small catheter in the radial artery. After a sufficient period of rest $(6 \mathrm{~h})$, they underwent a constant workload CPET for 12 minutes at $25 \%$ of their maximal previously determined work load. In the unloaded pedaling period, the subjects breathed ambient air. In the first 4 minutes (stage 1) of loaded pedaling they breathed ambient air, then $2 \% \mathrm{CO}_{2} / 21 \%$ $\mathrm{O}_{2}$ balanced with $\mathrm{N}_{2}$ during the next 4 minutes (stage 2), and then ambient air again for the last 4 minutes (stage 3). Whenever possible the constant workload CPET was repeated at least 1 hour later with $1 \% \mathrm{CO}_{2}$ at stage 2. During constant workload CPET 
patients breathed through a T-shaped tube connected to 1-way inspiratory and expiratory valves. The former was connected to a large low pressure balloon filled with room air or the $1 \%$ or $2 \% \mathrm{CO}_{2}$ mixture, as required by the protocol. Arterial blood samples were collected at the end of each stage. In 7 patients randomly selected, the constant work test was repeated with the use of a $1 \%$ $\mathrm{CO}_{2}$ mixture with the same temporal sequence. That night, all patients underwent an overnight respiratory monitoring study with measurement of nasobuccal air flow, chest and abdominal movement, oxygen saturation $\left(\mathrm{SaO}_{2}\right)$, and heart rate with the use of the Pamela Sleep Recorder (Medatecs, Brussels, Belgium).

\section{Day 2}

The next day, patients repeated the ramp CPET with arterial blood gas samples following the day 1 protocol 1 hour after the administration of $500 \mathrm{mg}$ intravenous acetazolamide. In this protocol, the addition of inhaled $\mathrm{CO}_{2}$ in the 2 nd phase was not studied. Thereafter, treatment with $500 \mathrm{mg}$ acetazolamide every 8 hours was started.

\section{Day 3}

On the 3rd day the patients again underwent the same testing as on day 2, but now after having received a total of $2 \mathrm{~g}$ acetazolamide (500 mg intravenously on day 1 , followed by $3500 \mathrm{mg}$ oral doses every 8 hours). Then overnight respiratory event monitoring was again performed.

We analyzed the following ramp CPET parameters performed under the 3 different conditions (basal, and after "acute" and "prolonged" acetazolamide administration): $\mathrm{VO}_{2} \quad(\mathrm{~mL} / \mathrm{min})$, $\mathrm{VO}_{2} / \mathrm{kg}\left(\mathrm{mL} \mathrm{min}{ }^{-1} \mathrm{~kg}^{-1}\right), \mathrm{VCO}_{2}(\mathrm{~mL} / \mathrm{min}), \mathrm{V}_{\mathrm{E}}(\mathrm{L} / \mathrm{min}), \mathrm{PetCO}_{2}$ $(\mathrm{mm} \mathrm{Hg})$, end-tidal $\mathrm{O}_{2}\left(\mathrm{PetO}_{2} ; \mathrm{mm} \mathrm{Hg}\right), \mathrm{Vt}(\mathrm{L})$, respiratory rate (RR; breaths/min), heart rate (HR; beats/min), $\mathrm{O}_{2}$ pulse $\left(\mathrm{VO}_{2} /\right.$ HR), work load achieved (W), and exercise tolerance (min). Peak exercise HR and gas exchange data were averaged over 30 -second intervals. During exercise, we also recorded the kinetics of $\mathrm{V}_{\mathrm{E}} / \mathrm{VCO}_{2}$ (ventilatory equivalents for $\mathrm{CO}_{2}$ ) and the $\mathrm{VO}_{2} /$ work relationships. The $\mathrm{PB}$ duration was determined from the beginning of exercise (\% of total exercise duration); number of cycles of PB during exercise, length of the first cycle of PB during exercise (s), $\mathrm{V}_{\mathrm{E}}$ and $\mathrm{Vt}$ measurements at peak and nadir of $\mathrm{PB}$ cycles (mean of the first 3 cycles), and maximum value of $\mathrm{Vt}$ and $\mathrm{V}_{\mathrm{E}}$ during exercise and at $\mathrm{PB}$ disappearance were also determined. Arterial blood gas analysis included measurement of $\mathrm{pH}, \mathrm{PO}_{2}, \mathrm{PCO}_{2}, \mathrm{HCO}_{3}{ }^{-}$, and $\mathrm{SaO}_{2 \%}$.

During constant work rate CPET, we analyzed the following parameters at the end of the 4th, 8th, and 12th minutes: presence of $\mathrm{PB}$ during each exercise stage, peak and nadir values of $\mathrm{V}_{\mathrm{E}}$ and $\mathrm{Vt}$, mean values during $\mathrm{CO}_{2}$ inhalation if $\mathrm{PB}$ disappeared, peak and nadir of the cycles if not, and the maximum values of $\mathrm{Vt}$ and $\mathrm{V}_{\mathrm{E}}$, along with arterial blood gas values.

To determine the disappearance of PB during both ramp and constant work rate exercise tests, we considered $\mathrm{Vt}$ as reference variable and defined $P B$ cessation when the amplitude of $V_{E}$ swings was $<10 \%$. To do so, data were evaluated by visual inspection and graphically measured. An example is presented in Figure 4 (bottom).

We analyzed the sleep respiratory events, recorded both in the basal condition and after prolonged administration of acetazolamide with the use of the following criteria. Apnea was defined as cessation of air flow that lasted $\geq 10$ seconds. Central apnea was identified by air flow cessation together with absence of

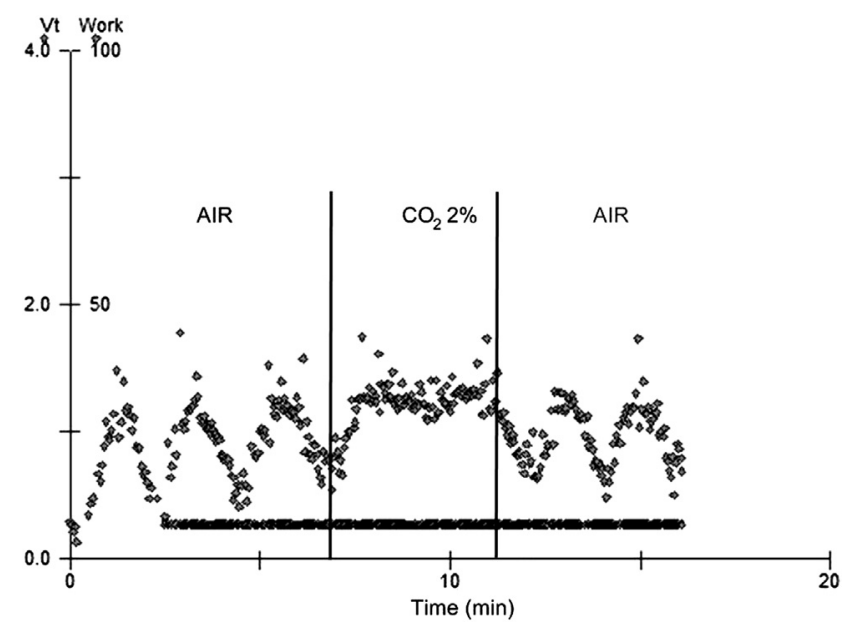

Fig. 2. Example of a constant workload test with disappearance of periodic breathing during $2 \% \mathrm{CO}_{2}$ inhalation. $\mathrm{Vt}$, tidal volume.

thoraco-abdominal movements, whereas obstructive apnea was defined as air flow cessation in the presence of thoracoabdominal movements. Hypopnea was defined as a $\geq 50 \%$ decrease in the sum of thoraco-abdominal movements lasting $\geq 10$ seconds followed by a reduction of $\mathrm{SaO}_{2}$ of $\geq 4 \%$. The presence of PB during sleep was visually assessed. ${ }^{7}$ Specifically, the presence of $\mathrm{PB}$ during sleep was visually assessed considering $\mathrm{PB}$ to be an oscillatory pattern in ventilation with a period of $\sim 60$ s characterized by phases of hyperventilation and central apnea or hypopnea. ${ }^{10}$ From these data we calculated the apnea/hypopnea index, apnea mean duration time, mean $\mathrm{SaO}_{2}$ during sleep, mean nadir $\mathrm{SaO}_{2}$ during sleep, and time with $\mathrm{SaO}_{2}<90 \%$.

\section{Statistical Analysis}

Data are presented as mean \pm SD. Analysis of variance was used for repeated measurements. Data were reported in an Excel data file and analyzed with SPSS software (version 10.0; SPSS, Chicago, Illinois). Comparisons were made with the use of Student $t$ paired test with Bonferroni corrections for initial and final values and for peak and nadir values, and a $P$ value of $<.05$ was considered to be significant.

\section{Results}

The characteristics of the 20 study patients are summarized in Table 1 . All were male with a mean age of 69 years with severe HF (mean LVEF 27\%, peak $\mathrm{VO}_{2} 12.4 \pm 4.7$ $\mathrm{mL} \mathrm{kg} \mathrm{min}^{-1}, \mathrm{VE} / \mathrm{VCO}_{2} 51.7 \pm 7.3$ ), and $35 \%$ had ischemic and $65 \%$ nonischemic etiologies. Typical for the therapy of this group, most were on beta-blockers, diuretics, and antiangiotensin therapies. Other medications used in $\leq 50 \%$ of the patients included digoxin, amiodarone, mineralocorticoid antagonists, and acetylsalicylic acid. Acetazolamide treatment did not influence diuresis, body weight, or serum electrolytes. Indeed, before acetazolamide and at day 3, diuresis, body weight, and serum $\mathrm{Na}^{+}$, $\mathrm{K}^{+}$, and $\mathrm{Cl}^{-}$were, respectively, $1,915 \pm 500 \mathrm{~mL} / 24 \mathrm{~h}$ and $1,919 \pm 933 \mathrm{~mL} / 24 \mathrm{~h}, 75 \pm 53 \mathrm{~kg}$ and $75 \pm 53 \mathrm{~kg}, 140 \pm$ 


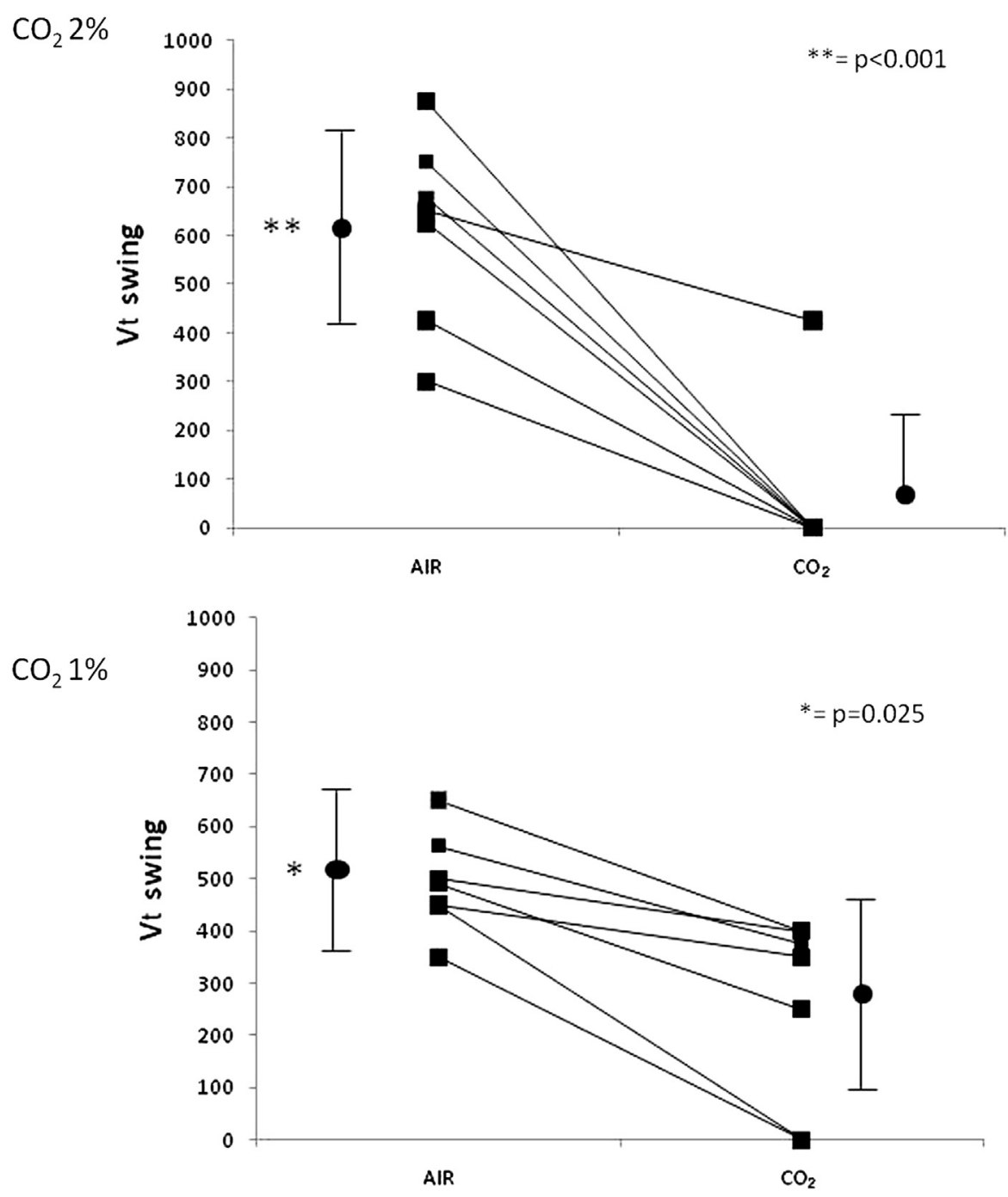

Fig. 3. Swing (difference between peak and nadir) of tidal volume $(\mathrm{Vt})$ at constant-workload cardiopulmonary exercise test during air and $2 \%$ (top) and $1 \%$ (bottom) inhalation of $\mathrm{CO}_{2}$ in the 7 patients who performed both tests.

$0 \mathrm{meq} / \mathrm{L}$ and $139 \pm 9 \mathrm{meq} / \mathrm{L}, 4.2 \pm 2.5 \mathrm{meq} / \mathrm{L}$ and $4.0 \pm$ $0.4 \mathrm{meq} / \mathrm{L}$, and $104 \pm 4 \mathrm{meq} / \mathrm{L}$ and $105 \pm 5 \mathrm{meq} / \mathrm{L}$.

\section{Effects of $\mathrm{CO}_{2}$ Inhalation on PB During Exercise}

$\mathbf{V}_{\mathbf{E}}$ (Table 2; Figs. 2 and 3). At rest, before constant work rate exercise (while sitting on the bike), and during ambient air breathing (stage 1), PB was evident in all of the patients. With $2 \% \mathrm{CO}_{2}$ inhalation (stage 2), PB disappeared in all but 1 case. In that patient, although PB was still detectable, the amplitude of $\mathrm{Vt}$ swing (difference between peak and nadir $\mathrm{Vt})$ was markedly reduced $(0.70 \mathrm{~L}$ during stage 1 and $0.35 \mathrm{~L}$ during stage 2). After resuming air inhalation in stage $3, \mathrm{~PB}$ recurred in all patients with the same pattern as before the $\mathrm{CO}_{2}$ challenge. Peak and nadir values of $\mathrm{Vt}$ and $\mathrm{V}_{\mathrm{E}}$ measured during air inhalation (stages 1 and 3), and mean values of $\mathrm{Vt}$ and $\mathrm{V}_{\mathrm{E}}$ during $2 \% \mathrm{CO}_{2}$ inhalation (stage 2), when $\mathrm{PB}$ disappeared in the 20 patients who performed the constant rate test with $2 \% \mathrm{CO}_{2}$ inhalation, are presented in Table 2. An example of PB cessation with $2 \%$ $\mathrm{CO}_{2}$ inhalation is shown in Figure 2. $\mathrm{CO}_{2}$ inhalation was evaluated with $1 \%$ and $2 \%$ in 7 of the 20 subjects according to their willingness and personal availability at the end of a long working day. When compared with $2 \% \mathrm{CO}_{2}$, which suppressed $\mathrm{PB}$ in all but 1 subject, only 2 subjects breathing $1 \% \mathrm{CO}_{2}$ had disappearance of PB (Fig. 3). Although $1 \%$ $\mathrm{CO}_{2}$ inhalation caused a reduction in the $\mathrm{Vt}$ variation, it was less than during $2 \% \mathrm{CO}_{2}$ inhalation $(P=.010)$.

Gas Exchange (Table 3). Arterial blood gas values measured at the end of each exercise stage showed a statistically significant increase of $\mathrm{PO}_{2}$ by $12 \pm 2.6 \mathrm{~mm} \mathrm{Hg}$ and of $\mathrm{SaO}_{2}$ by $0.6 \pm 6.6 \%$, with a reduction of $\mathrm{pH}$ by $-0.02 \pm 2.02(P=.001$ for all $)$, with $2 \% \mathrm{CO}_{2}$. With $1 \%$ $\mathrm{CO}_{2}$ breathing $(\mathrm{n}=7)$, we observed smaller similar directional changes in all values, but they did not reach statistical significance compared with the same patients breathing $2 \% \mathrm{CO}_{2}$.

\section{Effects of Acetazolamide Administration}

Data at Rest (Tables 4 and 5). No statistically significant differences were apparent in the cardiorespiratory parameters at rest (sitting on the bike) following the acute 

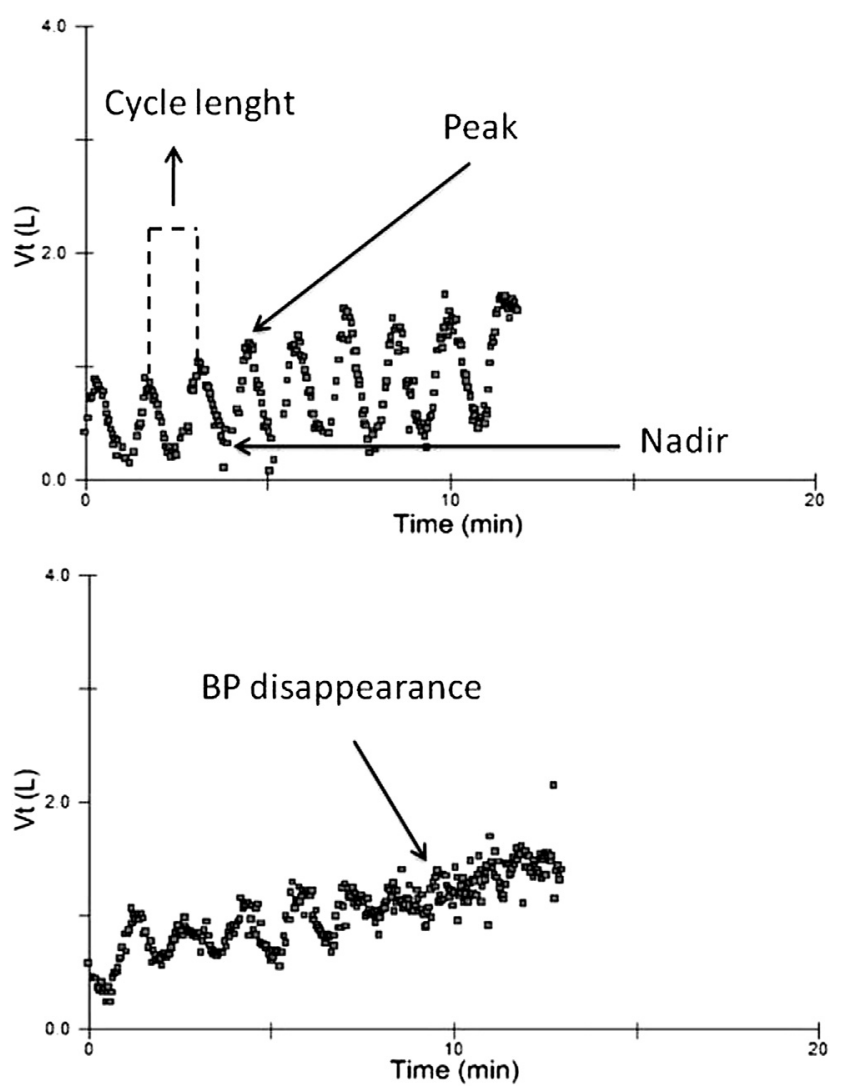

Fig. 4. Example of a ramp-workload cardiopulmonary exercise test in basal condition (top) and with earlier disappearance of periodic breathing after chronic administration of acetazolamide (bottom). Cycle length and tidal volume $(\mathrm{Vt})$ peak and nadir during periodic breathing (BP) are indicated.

administration of acetazolamide, although $\mathrm{V}_{\mathrm{E}}$ and $\mathrm{Vt}$ had suggestive upward trends. After prolonged administration $(2 \mathrm{~g}$ over $24 \mathrm{~h}), \mathrm{V}_{\mathrm{E}}$ was increased significantly owing to

Table 1. Patient Characteristics

\begin{tabular}{lc}
\hline $\mathrm{n}$ & 20 \\
Sex $(\mathrm{M} / \mathrm{F})$ & $20 / 0$ \\
Age (y) & $69.1 \pm 1.9$ \\
NYHA & $2.9 \pm 9.7$ \\
LVEF $(\%)$ & $27.2 \pm 7.9$ \\
LVDV (mL) & $210.7 \pm 64.4$ \\
LVDVI (mL/m $\left.{ }^{2}\right)$ & $112.6 \pm 30.5$ \\
BMI $\left(\mathrm{kg} / \mathrm{cm}^{2}\right)$ & $24.5 \pm 3.33$ \\
Therapy & \\
Beta-blockers & $80 \%$ \\
ACE-I/ARB & $80 \%$ \\
Diuretics & $90 \%$ \\
Antialdosteronics & $35 \%$ \\
Amiodarone & $50 \%$ \\
ASA & $40 \%$ \\
Digitalis & $15 \%$ \\
Etiology & \\
Ischemic & $35 \%$ \\
Nonischemic & $65 \%$ \\
\hline
\end{tabular}

NYHA, New York Heart Association functional class; LVEF, left ventricular ejection fraction; LVDV, left ventricular diastolic volume; LVDVI, left ventricular diastolic volume index; BMI, body mass index; ACE-I, angiotensin-converting enzyme inhibitor; ARB, angiotensin II receptor blocker; ASA, acetylsalicylic acid. an increase in $\mathrm{Vt}(+0.11 \pm 1.13 \mathrm{~L} ; P=.003)$, although the RR was not changed significantly. Consequently, Pet$\mathrm{CO}_{2}$ decreased $(-2.59 \pm 9.7 \mathrm{~mm} \mathrm{Hg} ; P<.001)$ and $\mathrm{PetO}_{2}$ increased $(+4.62 \pm 2.43 \mathrm{~mm} \mathrm{Hg} ; P=.001)$. A slight, but significant, reduction in HR was also observed. No significant differences in resting $\mathrm{VO}_{2}$ and $\mathrm{VCO}_{2}$ were detected. Acute acetazolamide generated no statistically significant changes in any arterial blood gas parameter, most importantly no change in $\mathrm{HCO}_{3}{ }^{-}$, reflecting an insufficient time for the drug to have caused any quantitative renal bicarbonate loss. $\mathrm{PCO}_{2}$ and $\mathrm{PO}_{2}$ were slightly higher, suggestive of a higher $\mathrm{V}_{\mathrm{E}}$ and a slight impairment of pulmonary $\mathrm{CO}_{2}$ excretion from red cell and vascular endothelial cell CA inhibition, ${ }^{12}$ but none of these changes reached statistical significance. In contrast, prolonged acetazolamide generated a statistically significant metabolic acidosis (lower $\mathrm{pH}$ and lower $\mathrm{HCO}_{3}{ }^{-}$) from renal CA inhibition resulting in a greater $\mathrm{V}_{\mathrm{E}}$ and arterial $\mathrm{PO}_{2} . \mathrm{SaO}_{2}$ was not increased, reflecting a right shift in the hemoglobin dissociation curve arising from the Bohr Effect.

Data at Peak Exercise (Tables 5 and 6). All subjects gave a full effort as indicated by achievement of a discernible ventilatory threshold (data not shown) and a fall in $\mathrm{HCO}_{3}{ }^{-}$of 3-4 $\mathrm{mmol} / \mathrm{L}$. Maximum HR was lower than age predicted owing to the high prevalence of beta-blocker use and possibly intrinsic chronotropic insufficiency typical in this patient group. No differences were observed among cardiorespiratory parameters at peak exercise after acute acetazolamide infusion compared with the control study. However, after prolonged administration of acetazolamide, maximum work load was significantly reduced by $\sim 10 \%(P<.02)$. We also observed a significant decrease in peak $\mathrm{VO}_{2}$ and peak $\mathrm{VCO}_{2}$. Total $\mathrm{V}_{\mathrm{E}}$ at peak exercise did not change significantly, but $\mathrm{V}_{\mathrm{E}}$ at any given work load was higher, as reflected in the lower $\mathrm{PetCO}_{2}$ and higher $\mathrm{V}_{\mathrm{E}} / \mathrm{VCO}_{2}$ values (data not shown). After prolonged acetazolamide, the $\mathrm{V}_{\mathrm{E}} / \mathrm{VCO}_{2}$ slope increased. The arterial blood gas values during all stages of exercise and up to peak exercise are presented in Table 5. With acute acetazolamide administration, $\mathrm{PaCO}_{2}$ was slightly higher and $\mathrm{pH}$ slightly lower compared with no treatment. With prolonged acetazolamide $\mathrm{pH}$ and $\mathrm{HCO}_{3}{ }^{-}$were statistically significantly lower and $\mathrm{PaO}_{2}$ higher than with no treatment as well as different from acute acetazolamide treatment, reflecting the stronger ventilatory stimulus of the metabolic acidosis of prolonged administration.

PB During Exercise (Table 7). In the resting conditions, PB was present throughout the entire exercise in 6 patients, whereas it disappeared before the end of exercise in the remaining 14 patients. After acute administration of acetazolamide, PB disappeared altogether in 1 patient, and after prolonged administration PB disappeared in 7 patients. In the patients in whom PB was still detectable, its duration was significantly reduced after both acute and prolonged administration. As a percentage of exercise duration, PB was present $80 \pm 26 \%, 65 \pm 28 \%$, and $43 \pm 39 \%$ of the time before and after acute and prolonged acetazolamide administration, respectively $(P=.121$ basal vs 
Table 2. Constant-Workload Exercise Test During Room Air and 2\% $\mathrm{CO}_{2}$ Breathing $(\mathrm{n}=20)$

\begin{tabular}{|c|c|c|c|c|c|}
\hline & \multicolumn{2}{|c|}{ Stage 1 (Air) $(\mathrm{n}=20)$} & \multirow{2}{*}{$\frac{\text { Stage } 2\left(\mathrm{CO}_{2}\right), \text { No PB }(\mathrm{n}=19)}{\text { Mean }}$} & \multicolumn{2}{|c|}{ Stage 3 (Air) $(\mathrm{n}=20)$} \\
\hline & Peak & Nadir & & Peak & Nadir \\
\hline $\mathrm{Vt}(\mathrm{L})$ & $1.18 \pm 0.23$ & $0.56 \pm 0.16$ & $1.29 \pm 0.22$ & $1.23 \pm 0.21$ & $0.71 \pm 0.19$ \\
\hline $\mathrm{V}_{\mathrm{E}}(\mathrm{L} / \mathrm{min})$ & $27.9 \pm 6.3$ & $14.6 \pm 4.0$ & $33.3 \pm 6.4$ & $29.5 \pm 6.4$ & $18.9 \pm 4.6$ \\
\hline
\end{tabular}

VE, ventilation; Vt, tidal volume; PB, periodic breathing. Data reported are those recorded at minutes 4 (stage 1), 8 (stage 2), and 12 (stage 3) of the constant-workload exercise.

acute; $P=.001$ basal vs prolonged; $P=.060$ acute vs prolonged). $\mathrm{Vt}$ and $\mathrm{V}_{\mathrm{E}}$ values measured at the beginning of loaded pedaling (peak and nadir), at PB disappearance and as a maximum value observed throughout exercise, in basal condition and after acute and prolonged acetazolamide administration, are reported in Table 7. A significant reduction in number of $\mathrm{PB}$ cycles from the beginning of exercise and a significant increase in the PB cycle length (amplitude) were detected after acute and prolonged acetazolamide among patients in which PB was still present. An example of PB reduction after prolonged acetazolamide is shown in Figure 4.

Sleep Apnea (Table 8). Polysomnographic recordings of respiratory events during sleep were evaluatable both in the untreated condition and after prolonged administration of acetazolamide in 18/20 patients (in 1 patient the quality of recording after acetazolamide was not sufficient for evaluation, and 1 patient was intolerant of the monitoring equipment). In all recorded patients, significant sleep apnea was detectable in the untreated condition; however, in 2 patients the apnea/hypopnea index was below the cutoff of 10 . The apnea/hypopnea index significantly decreased after prolonged administration of acetazolamide, whereas the average duration of events did not change significantly. We also observed a significant increase of nocturnal mean
$\mathrm{SaO}_{2}$ and of the time with $\mathrm{SaO}_{2}<90 \%$, whereas no difference was observed in mean nadir $\mathrm{SaO}_{2}$.

\section{Discussion}

The important findings in this study are the following: 1) Inhalation of $2 \% \mathrm{CO}_{2}$ during submaximal exercise completely abolished $\mathrm{PB}$ during exercise in $95 \%$ of subjects with $\mathrm{HF}$, but $1 \% \mathrm{CO}_{2}$ inhalation was effective in suppressing $\mathrm{PB}$ in only one-third; 2) with $2 \% \mathrm{CO}_{2}$ the subjects reached a higher mean $\mathrm{V}_{\mathrm{E}}$ and $\mathrm{Vt}$ than the peak $\mathrm{V}_{\mathrm{E}}$ and $\mathrm{Vt}$ of the PB cycles; 3 ) acetazolamide given acutely (intravenously) was relatively ineffective in suppressing PB during exercise, but when given over 24 hours, long enough to generate a metabolic acidosis, PB was suppressed in 7 patients; 4) in those patients on prolonged acetazolamide but without PB suppression, the number of PB cycles was reduced and the length of each cycle was increased; and 5) prolonged acetazolamide reduced exercise capacity by $\sim 10 \%$ but improved sleep-disordered breathing with a reduction in the apnea-hypopnea index by $28 \%$, leading to an overall higher mean arterial oxygenation and less time spent below an $\mathrm{SaO}_{2}$ of $90 \%$. These data confirm and extend the work of others showing that changes in

Table 3. Arterial Blood Gas Analysis During $\mathrm{CO}_{2}$ Inhalation

\begin{tabular}{|c|c|c|c|c|c|c|c|}
\hline & \multirow[b]{2}{*}{ Stage 1 (Air) } & \multirow[b]{2}{*}{ Stage $2\left(\mathrm{CO}_{2}\right)$} & \multirow[b]{2}{*}{ Stage 3 (Air) } & \multirow[b]{2}{*}{ ANOVA } & \multicolumn{3}{|c|}{ Bonferroni } \\
\hline & & & & & Stage 1 vs 2 & Stage 2 vs 3 & Stage 1 vs 3 \\
\hline \multicolumn{8}{|l|}{$2 \% \mathrm{CO}_{2}(\mathrm{n}=20)$} \\
\hline $\mathrm{pH}$ & $7.46 \pm 6.05$ & $7.44 \pm 4.03$ & $7.45 \pm 5.03$ & $<.001$ & .001 & .208 & .307 \\
\hline $\mathrm{PO}_{2}(\mathrm{~mm} \mathrm{Hg})$ & $94.5 \pm 50.5$ & $107.4 \pm 40.3$ & $96.3 \pm 31.5$ & $<.001$ & $<.001$ & $<.001$ & .413 \\
\hline $\mathrm{PCO}_{2}(\mathrm{~mm} \mathrm{Hg})$ & $36.1 \pm 1.9$ & $37.2 \pm 2.5$ & $36.4 \pm 4.6$ & .376 & & & \\
\hline $\mathrm{HCO}_{3}^{-}(\mathrm{mmol} / \mathrm{L})$ & $26.3 \pm 3.1$ & $25.8 \pm 8.0$ & $26.0 \pm 0.2$ & .437 & & & \\
\hline $\mathrm{SaO}_{2}(\%)$ & $97.7 \pm 7.8$ & $98.3 \pm 3.5$ & $97.7 \pm 7.9$ & .001 & .001 & .001 & 1.000 \\
\hline \multicolumn{8}{|c|}{$2 \% \mathrm{CO}_{2}\left(\mathrm{n}=7\right.$ [patients who also underwent $\left.\left.1 \% \mathrm{CO}_{2}\right]\right)$} \\
\hline $\mathrm{pH}$ & $7.47 \pm 7.07$ & $7.45 \pm 5.05$ & $7.46 \pm 6.03$ & .267 & & & \\
\hline $\mathrm{PO}_{2}(\mathrm{~mm} \mathrm{Hg})$ & $92.9 \pm 93.2$ & $106.7 \pm 7.0$ & $95.4 \pm 44.0$ & .020 & .009 & .054 & .524 \\
\hline $\mathrm{PCO}_{2}(\mathrm{~mm} \mathrm{Hg})$ & $35.4 \pm 4.5$ & $35.9 \pm 9.5$ & $36.1 \pm 1.5$ & .804 & & & \\
\hline $\mathrm{HCO}_{3}^{-}(\mathrm{mmol} / \mathrm{L})$ & $26.3 \pm 3.6$ & $25.4 \pm 4.3$ & $26.2 \pm 2.1$ & .703 & & & \\
\hline $\mathrm{SaO}_{2}(\%)$ & $97.7 \pm 7.9$ & $98.4 \pm 4.2$ & $97.7 \pm 7.1$ & .183 & & & \\
\hline \multicolumn{8}{|l|}{$1 \% \mathrm{CO}_{2}(\mathrm{n}=7)$} \\
\hline $\mathrm{pH}$ & $7.47 \pm 7.05$ & $7.45 \pm 5.04$ & $7.46 \pm 6.04$ & .373 & & & \\
\hline $\mathrm{pO}_{2}(\mathrm{~mm} \mathrm{Hg})$ & $96.6 \pm 60.8$ & $100.6 \pm 62.1$ & $98.9 \pm 90.6$ & .401 & & & \\
\hline $\mathrm{pCO}_{2}(\mathrm{~mm} \mathrm{Hg})$ & $32.8 \pm 8.0$ & $34.5 \pm 55.0$ & $35.4 \pm 4.6$ & .150 & & & \\
\hline $\mathrm{HCO}_{3}^{-}(\mathrm{mmol} / \mathrm{L})$ & $24.8 \pm 8.5$ & $25.0 \pm 0.1$ & $25.8 \pm 8.9$ & .505 & & & \\
\hline $\mathrm{SaO}_{2}(\%)$ & $98.0 \pm 0.7$ & $98.1 \pm 1.7$ & $98.0 \pm 0.7$ & .444 & & & \\
\hline
\end{tabular}

ANOVA, analysis of variance; $\mathrm{PO}_{2}$, oxygen partial pressure; $\mathrm{PCO}_{2}$, carbon dioxide partial pressure; $\mathrm{HCO}_{3}^{-}$, bicarbonate; SaO $\mathrm{O}_{2}$, oxygen saturation. 
Table 4. Ramp-Protocol CPET: Data at Rest

Bonferroni

\begin{tabular}{|c|c|c|c|c|c|c|c|}
\hline & No therapy & Acute & Chronic & ANOVA & No Therapy vs Acute & No Therapy vs Chronic & Acute vs Chronic \\
\hline $\mathrm{VO}_{2}(\mathrm{~mL} / \mathrm{min})$ & $260 \pm 55$ & $251 \pm 82$ & $258 \pm 62$ & .87 & & & \\
\hline $\mathrm{VO}_{2} / \mathrm{kg}_{(\mathrm{mL} \mathrm{kg}}{ }^{-1} \mathrm{~min}^{-1}$ & $4.2 \pm 2.3$ & $3.5 \pm 5.6$ & $3.8 \pm 8.6$ & .629 & & & \\
\hline $\mathrm{VCO}_{2}(\mathrm{~mL} / \mathrm{min})$ & $203 \pm 36$ & $228 \pm 88$ & $225 \pm 54$ & .068 & & & \\
\hline $\mathrm{V}_{\mathrm{E}}(\mathrm{L} / \mathrm{min})$ & $11.7 \pm 7.0$ & $13.0 \pm 0.0$ & $13.8 \pm 8.8$ & .001 & .13 & .001 & .593 \\
\hline Vt (L) & $0.56 \pm 6.10$ & $0.60 \pm 0.09$ & $0.67 \pm 7.14$ & .003 & .075 & .002 & .062 \\
\hline $\mathrm{PetCO}_{2}(\mathrm{~mm} \mathrm{Hg})$ & $29.4 \pm 4.3$ & $28.9 \pm 9.4$ & $26.8 \pm 8.9$ & $<.001$ & 1 & $<.001$ & .002 \\
\hline $\mathrm{PetO}_{2}(\mathrm{~mm} \mathrm{Hg})$ & $112.9 \pm 9.2$ & $114.2 \pm 2.5$ & $117.5 \pm 5.7$ & .001 & .673 & .001 & .019 \\
\hline RR & $21.0 \pm 0.7$ & $21.8 \pm 8.6$ & $22.3 \pm 3.7$ & .271 & & & \\
\hline HR & $73 \pm 35$ & $71 \pm 12$ & $69 \pm 93$ & .016 & .741 & .019 & .106 \\
\hline $\mathrm{O}_{2}$ pulse (mL/beat) & $3.6 \pm 6.7$ & $3.8 \pm 8.0$ & $4.0 \pm 0.1$ & .082 & & & \\
\hline
\end{tabular}

ANOVA, analysis of variance; $\mathrm{VO}_{2}$, oxygen consumption; $\mathrm{VCO}_{2}, \mathrm{CO}_{2}$ production; $\mathrm{V}_{\mathrm{E}}$, ventilation; $\mathrm{Vt}$, tidal volume; PetCO $\mathrm{CO}_{2}$, end-tidal pressure of $\mathrm{CO}_{2}$; $\mathrm{PetO}_{2}$, end-tidal pressure of $\mathrm{O}_{2} ; \mathrm{RR}$, respiratory rate (breaths/min); HR, heart rate (beats $/ \mathrm{min}$ ).

prevailing $\mathrm{PCO}_{2}$, acid-base balance, and $\mathrm{CO}_{2}$ reaction kinetics act to reduce $\mathrm{PB}$ in $\mathrm{HF}$.

The regulation of breathing by the CNS is a complex process and arises from the medullary respiratory center, the output of which is influenced by a variety of factors, including cortical stimulation during the awake state, afferent signaling from the peripheral and central chemoreceptors, arterial baroreceptors, lung stretch receptors, musculoskeletal metaboreceptors, and numerous circulating vasoactive mediators that are altered in $\mathrm{HF}^{3}$ In addition to these tonic influences, time-dependent differences in arrival of these signals at the peripheral and central chemoreceptors and thence to the medullary respiratory controller also may be involved in stability or instability in breathing. ${ }^{17}$ Of the several mechanisms postulated to cause $\mathrm{PB}$ in HF, whether in sleep, wakefulness, or exercise, alterations involving changes in $\mathrm{CO}_{2}$ have received considerable attention. Experimental manipulations of $\mathrm{CO}_{2}$ and acid-base status by $\mathrm{CO}_{2}$ inhalation (as in the present study) and dead-space addition ${ }^{7}$ during exercise that reduce or

Table 5. Effect of Acetazolamide on Arterial Blood Gas Values

\begin{tabular}{|c|c|c|c|c|c|c|c|c|}
\hline & \multirow[b]{2}{*}{ Minute } & \multirow[b]{2}{*}{ Basal } & \multirow[b]{2}{*}{ Acute } & \multirow[b]{2}{*}{ Chronic } & \multirow[b]{2}{*}{ ANOVA } & \multicolumn{3}{|c|}{ Bonferroni } \\
\hline & & & & & & $\begin{array}{c}\text { No Therapy vs } \\
\text { Acute }\end{array}$ & $\begin{array}{l}\text { no Therapy vs } \\
\text { Chronic }\end{array}$ & $\begin{array}{l}\text { Acute vs } \\
\text { Chronic }\end{array}$ \\
\hline \multirow[t]{6}{*}{$\mathrm{pH}$} & 0 & $7.47 \pm 7.05$ & $7.45 \pm 5.04$ & $7.42 \pm 2.05$ & $<.001$ & .58 & $<.001$ & .00 \\
\hline & 2 & $7.47 \pm 7.04$ & $7.45 \pm 5.04$ & $7.42 \pm 2.04$ & $<.001$ & .04 & $<.001$ & .00 \\
\hline & 4 & $7.46 \pm 6.04$ & $7.45 \pm 5.04$ & $7.42 \pm 2.04$ & $<.001$ & .25 & $<.001$ & $<.001$ \\
\hline & 6 & $7.46 \pm 6.04$ & $7.45 \pm 5.03$ & $7.41 \pm 1.04$ & $<.001$ & .77 & $<.001$ & $<.001$ \\
\hline & $8 *$ & $7.47 \pm 7.04$ & $7.45 \pm 5.03$ & $7.42 \pm 2.04$ & .004 & .37 & .003 & .01 \\
\hline & Peak & $7.47 \pm 7.04$ & $7.46 \pm 6.03$ & $7.40 \pm 0.04$ & $<.001$ & 1.00 & $<.001$ & $<.001$ \\
\hline \multirow[t]{6}{*}{$\mathrm{PO}_{2}(\mathrm{~mm} \mathrm{Hg})$} & 0 & $92.8 \pm 81.6$ & $95.00 \pm 03.4$ & $101.2 \pm 20.5$ & $<.001$ & .89 & $<.001$ & .02 \\
\hline & 2 & $93.6 \pm 65.3$ & $92.37 \pm 72.8$ & $98.6 \pm 11.4$ & .008 & 1.00 & .012 & .02 \\
\hline & 4 & $91.5 \pm 53.3$ & $93.47 \pm 75.2$ & $101.4 \pm 41.6$ & .001 & 1.00 & .001 & .00 \\
\hline & 6 & $95.5 \pm 54.6$ & $95.79 \pm 94.8$ & $102.5 \pm 53.8$ & $<.001$ & 1.00 & $<.001$ & $<.001$ \\
\hline & $8 *$ & $101.2 \pm 24.2$ & $102.53 \pm 36.2$ & $104.3 \pm 4.6$ & .001 & 1.00 & .117 & .00 \\
\hline & Peak & $102.9 \pm 98.3$ & $104.57 \pm 77.4$ & $107.0 \pm 04.6$ & .015 & 1.00 & .068 & .01 \\
\hline \multirow[t]{6}{*}{$\mathrm{PCO}_{2}(\mathrm{~mm} \mathrm{Hg})$} & 0 & $36.7 \pm 7.8$ & $37.44 \pm 4.2$ & $35.4 \pm 4.6$ & .09 & & & \\
\hline & 2 & $35.9 \pm 9.3$ & $37.76 \pm 6.9$ & $35.3 \pm 3.1$ & .041 & .193 & 1.000 & .038 \\
\hline & 4 & $36.0 \pm 0.9$ & $37.09 \pm 9.7$ & $35.5 \pm 3.2$ & .118 & & & \\
\hline & 6 & $35.5 \pm 5.1$ & $36.82 \pm 2.5$ & $35.7 \pm 7.4$ & .29 & & & \\
\hline & $8 *$ & $33.0 \pm 0.6$ & $35.75 \pm 5.2$ & $34.3 \pm 3.1$ & .022 & .063 & .881 & .020 \\
\hline & Peak & $32.6 \pm 6.9$ & $32.96 \pm 6.6$ & $34.3 \pm 3.0$ & .584 & & & \\
\hline \multirow[t]{6}{*}{$\mathrm{HCO}_{3}{ }^{-}(\mathrm{mmol} / \mathrm{L})$} & 0 & $26.8 \pm 8.2$ & $26.68 \pm 8.1$ & $23.3 \pm 2.3$ & $<.001$ & 1.00 & $<.001$ & $<.001$ \\
\hline & 2 & $26.6 \pm 6.4$ & $26.52 \pm 2.1$ & $23.2 \pm 2.1$ & $<.001$ & 1.00 & $<.001$ & $<.001$ \\
\hline & 4 & $26.3 \pm 3.9$ & $26.18 \pm 8.0$ & $23.4 \pm 2.0$ & $<.001$ & 1.00 & $<.001$ & $<.001$ \\
\hline & 6 & $26.0 \pm 2.6$ & $26.06 \pm 6.5$ & $23.2 \pm 2.1$ & $<.001$ & 1.00 & $<.001$ & $<.001$ \\
\hline & $8 *$ & $24.6 \pm 6.6$ & $25.65 \pm 5.3$ & $22.7 \pm 7.1$ & $<.001$ & .68 & $<.001$ & $<.001$ \\
\hline & Peak & $23.6 \pm 6.5$ & $24.19 \pm 9.9$ & $21.7 \pm 7.1$ & $<.001$ & 1.00 & .004 & $<.001$ \\
\hline \multirow[t]{6}{*}{$\mathrm{SaO}_{2}(\%)$} & 0 & $97.5 \pm 5.1$ & $97.5 \pm 5.0$ & $97.92 \pm 2.7$ & .127 & & & \\
\hline & 2 & $97.3 \pm 3.7$ & $97.3 \pm 3.0$ & $97.69 \pm 9.9$ & .109 & & & \\
\hline & 4 & $97.3 \pm 3.4$ & $97.2 \pm 2.7$ & $97.88 \pm 8.8$ & .075 & & & \\
\hline & 6 & $97.5 \pm 5.2$ & $97.6 \pm 6.0$ & $97.82 \pm 2.9$ & .067 & & & \\
\hline & $8 *$ & $97.9 \pm 9.0$ & $98.0 \pm 0.9$ & $97.98 \pm 8.9$ & .221 & & & \\
\hline & Peak & $97.7 \pm 7.4$ & $98.0 \pm 0.2$ & $98.00 \pm 0.1$ & .111 & & & \\
\hline
\end{tabular}

Abbreviations as in Table 3.

$* \mathrm{n}=14$. 
Table 6. Ramp-Protocol CPET: Peak Exercise Data

\begin{tabular}{|c|c|c|c|c|c|c|c|}
\hline & \multirow[b]{2}{*}{ No Therapy } & \multirow[b]{2}{*}{ Acute } & \multirow[b]{2}{*}{ Chronic } & \multirow[b]{2}{*}{ ANOVA } & \multicolumn{3}{|c|}{ Bonferroni } \\
\hline & & & & & $\begin{array}{c}\text { No Therapy vs } \\
\text { Acute }\end{array}$ & $\begin{array}{l}\text { No Therapy vs } \\
\text { Chronic }\end{array}$ & Acute vs Chronic \\
\hline Work load (W) & $61.3 \pm 32.1$ & $58.9 \pm 92.0$ & $55.9 \pm 90.9$ & .021 & .311 & .019 & .051 \\
\hline Exercise tolerance (min) & $9.6 \pm 6.6$ & $9.2 \pm 2.7$ & $8.8 \pm 8.8$ & .086 & & & \\
\hline $\mathrm{VO}_{2}(\mathrm{~mL} / \mathrm{min})$ & $920 \pm 019$ & $862 \pm 232$ & $849 \pm 908$ & .045 & .121 & .036 & 1 \\
\hline $\mathrm{VO}_{2} / \mathrm{kg}\left(\mathrm{mL} \mathrm{kg}^{-1} \mathrm{~min}^{-1}\right)$ & $12.4 \pm 4.7$ & $11.5 \pm 5.6$ & $11.5 \pm 5.0$ & .043 & .065 & .054 & 1 \\
\hline $\mathrm{VO}_{2} \%$ of predicted value & $46 \pm 61$ & $44 \pm 42$ & $43 \pm 31$ & .039 & .11 & .032 & 1 \\
\hline $\mathrm{VCO}_{2}(\mathrm{~mL} / \mathrm{min})$ & $945 \pm 541$ & $874 \pm 473$ & $836 \pm 622$ & .02 & .151 & .014 & .627 \\
\hline $\mathrm{VE}(\mathrm{L} / \mathrm{min})$ & $47.4 \pm 4.6$ & $43.2 \pm 21.4$ & $45.7 \pm 7.6$ & .077 & & & \\
\hline $\mathrm{Vt}(\mathrm{L})$ & $1.33 \pm 3.25$ & $1.27 \pm 7.25$ & $1.39 \pm 9.25$ & .031 & .516 & .341 & .023 \\
\hline $\mathrm{PetCO}_{2}(\mathrm{~mm} \mathrm{Hg})$ & $27.6 \pm 6.9$ & $26.6 \pm 6.7$ & $24.3 \pm 3.0$ & $<.001$ & .06 & $<.001$ & .001 \\
\hline $\mathrm{PetO}_{2}(\mathrm{~mm} \mathrm{Hg})$ & $120.4 \pm 4.4$ & $120.4 \pm 4.6$ & $122.3 \pm 3.2$ & .121 & & & \\
\hline RR & $33.1 \pm 1.3$ & $32.7 \pm 7.1$ & $31.3 \pm 3.1$ & .08 & & & \\
\hline HR & $105 \pm 51$ & $103 \pm 31$ & $98 \pm 80$ & .028 & 1 & .02 & .158 \\
\hline $\mathrm{O}_{2}$ pulse (mL/beat) & $9.4 \pm 4.9$ & $8.4 \pm 4.2$ & $8.8 \pm 8.1$ & .034 & .477 & .069 & .069 \\
\hline $\mathrm{VE} / \mathrm{VCO}_{2}$ at peak & $51.7 \pm 9.3$ & $51.0 \pm 9.1$ & $56.5 \pm 11.8$ & .022 & 1 & .026 & .072 \\
\hline \multicolumn{8}{|l|}{ Slope } \\
\hline $\mathrm{VE} / \mathrm{VCO}_{2}$ & $39.0 \pm 0.7$ & $39.7 \pm 7.1$ & $43.5 \pm 5.2$ & .022 & 1 & .015 & .12 \\
\hline $\mathrm{VO}_{2} /$ work $\left(\mathrm{mL} \min ^{-1} \mathrm{~W}^{-1}\right)$ & $8.9 \pm 9.7$ & $9.3 \pm 3.7$ & $8.9 \pm 9.7$ & .334 & & & \\
\hline
\end{tabular}

Abbreviations as in Tables 3 and 4.

abolish PB appear to be explained well by an increase in the eupneic $\mathrm{PCO}_{2}$ to apneic $\mathrm{PCO}_{2}$ threshold. Both maneuvers, by raising eupneic $\mathrm{PCO}_{2}$, increase this difference and prevent or minimize the potential that any period of increased $\mathrm{V}_{\mathrm{E}}$, by whatever stimulus, will drive arterial $\mathrm{PCO}_{2}$ below the apneic threshold. A fall below this threshold initiates a cessation of breathing that is ultimately ended when the combined strong stimuli of a falling arterial $\mathrm{PO}_{2}$ and rising arterial $\mathrm{PCO}_{2}$ evoke a brisk hyperventilatory response that then drives the $\mathrm{PCO}_{2}$ down again below the apneic threshold to set up a vicious cycle of PB.

\section{Effects of Inhaled $\mathrm{CO}_{2}$ on PB and Gas Exchange}

Our finding that $\mathrm{CO}_{2}$ inhalation during exercise abolishes $\mathrm{PB}$ in a dose-dependent manner is fully consistent with the paradigm that an elevation of eupneic $\mathrm{PCO}_{2}$ without a change in the apneic $\mathrm{PCO}_{2}$ threshold will act to stabilize breathing against a strong background of ventilatory stimulation such as exists in HF. This has already been demonstrated in these patients during sleep, ${ }^{8-10}$ and we show for the first time the same efficacy in exercise. We also found that arterial $\mathrm{PO}_{2}$ was significantly higher with inhaled $\mathrm{CO}_{2}$, likely a result of both an increase in $\mathrm{V}_{\mathrm{E}}$ and a reduction in ventilation-perfusion mismatching. ${ }^{18}$ The tendency to PB may arise from an augmentation in the summed chemoreceptor inputs to respiratory drive, which are $\mathrm{O}_{2}$ (peripheral) and $\mathrm{CO}_{2}$ (peripheral and central) dependent. Although the slight rise in $\mathrm{PCO}_{2}$ would be stimulating to ventilatory drive, the concurrent rise in $\mathrm{PO}_{2}$ of $13 \mathrm{~mm} \mathrm{Hg}$ (with $2 \% \mathrm{CO}_{2}$ ) or $4 \mathrm{~mm} \mathrm{Hg}$ (with $1 \% \mathrm{CO}_{2}$ ) may exert a counterinhibitory effect via withdrawal of peripheral

Table 7. Effect of Acetazolamide on Periodic Breathing Cycle

\begin{tabular}{|c|c|c|c|c|c|c|c|}
\hline & \multirow[b]{2}{*}{ Basal } & \multirow[b]{2}{*}{ Acute } & \multirow[b]{2}{*}{ Chronic } & \multirow[b]{2}{*}{ ANOVA } & \multicolumn{3}{|c|}{ Bonferroni } \\
\hline & & & & & $\begin{array}{c}\text { No Therapy vs } \\
\text { Acute }\end{array}$ & $\begin{array}{l}\text { No Therapy vs } \\
\text { Chronic }\end{array}$ & $\begin{array}{l}\text { Acute vs } \\
\text { Chronic }\end{array}$ \\
\hline \multicolumn{8}{|l|}{$\mathrm{V}_{\mathrm{E}}(\mathrm{L} / \mathrm{min})$} \\
\hline Peak $(*)$ & $22.6 \pm 6.9(\mathrm{n}=20)$ & $22.0 \pm 0.3(\mathrm{n}=19)$ & $20.8 \pm 8.3(\mathrm{n}=13)$ & .443 & & & \\
\hline Nadir $(*)$ & $8.0 \pm 0.6(\mathrm{n}=20)$ & $9.6 \pm 6.9(\mathrm{n}=19)$ & $8.5 \pm 5.7(\mathrm{n}=13)$ & .014 & .012 & .157 & .604 \\
\hline Disappearance & $32.8 \pm 80.2(\mathrm{n}=14)$ & $28.7 \pm 7.4(\mathrm{n}=17)$ & $32.2 \pm 20.7(\mathrm{n}=13)$ & .687 & & & \\
\hline Maximum & $48.4 \pm 40.9(\mathrm{n}=20)$ & $43.9 \pm 91.2(\mathrm{n}=19)$ & $45.4 \pm 42.9(n=13)$ & .248 & & & \\
\hline \multicolumn{8}{|c|}{ 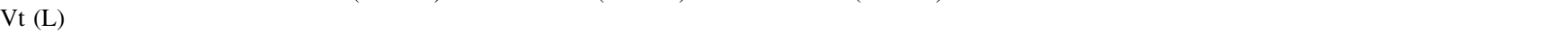 } \\
\hline Peak $(*)$ & $1.0 \pm 0.2(\mathrm{n}=20)$ & $0.9 \pm 9.3(\mathrm{n}=19)$ & $0.9 \pm 9.2(\mathrm{n}=13)$ & .509 & & & \\
\hline Nadir $(*)$ & $0.3 \pm 3.1(\mathrm{n}=20)$ & $0.4 \pm 4.1(n=19)$ & $0.4 \pm 4.1(\mathrm{n}=13)$ & .021 & .133 & .014 & .169 \\
\hline Disappearance & $1.3 \pm 3.2(\mathrm{n}=14)$ & $1.1 \pm 1.3(\mathrm{n}=17)$ & $1.1 \pm 1.3(\mathrm{n}=13)$ & .427 & & & \\
\hline Maximum & $1.5 \pm 5.2(\mathrm{n}=20)$ & $1.4 \pm 4.2(\mathrm{n}=19)$ & $1.5 \pm 5.3(\mathrm{n}=13)$ & .348 & & & \\
\hline No. of cycles & $5.0 \pm 0.9(\mathrm{n}=20)$ & $3.6 \pm 6.9(\mathrm{n}=19)$ & $2.9 \pm 9.9(n=13)$ & .002 & 0.157 & .001 & .18 \\
\hline $\begin{array}{l}\text { Length of 1st cycle } \\
\text { of exer. (s) }\end{array}$ & $83.1 \pm 16(n=20)$ & $88.9 \pm 99.9(n=19)$ & $101.9 \pm 99.6(n=13)$ & .003 & 1 & .002 & .042 \\
\hline
\end{tabular}

Abbreviations as in Table 4.

*Peak and nadir were calculated as mean value of the first 2 cycles from the beginning of exercise. 
Table 8. Effect of Acetazolamide on Sleep Apnea

\begin{tabular}{lccc}
\hline & Basal & $\begin{array}{c}\text { Chronic } \\
\text { Therapy }\end{array}$ & $P$ Value \\
\hline $\begin{array}{l}\text { Apnea/hypopnea Index } \\
\quad(\text { events/h) }\end{array}$ & $30.8 \pm 13.8$ & $21.1 \pm 16.9$ & .003 \\
Mean apnea duration (s) & $26.9 \pm 6.1$ & $28.4 \pm 7.0$ & .431 \\
Mean $\mathrm{SaO}_{2}(\%)$ & $93.2 \pm 2.3$ & $94.1 \pm 2.2$ & .005 \\
Minimal $\mathrm{SaO}_{2}(\%)$ (nadir) & $86.6 \pm 2.5$ & $86.1 \pm 4.6$ & .677 \\
Time at $\mathrm{SaO}_{2}<90 \%$ (min) & $65.6 \pm 86.1$ & $37.1 \pm 54.8$ & .035 \\
$\%$ of time at $\mathrm{SaO}_{2}<90 \%$ & $12.76 \pm 15.5$ & $9.6 \pm 15.5$ & .031 \\
\hline
\end{tabular}

$\mathrm{SaO}_{2}$, oxygen saturation.

chemoreceptor afferent signaling. Although $\mathrm{O}_{2}$-sensitive carotid body output is not generally thought to be important when $\mathrm{PaO}_{2}$ is $>70 \mathrm{~mm} \mathrm{Hg}$, owing to the very hyperbolic nature of the hypoxic ventilatory response, some peripheral chemoreceptor activity is still present at normal physiologic $\mathrm{PaO}_{2}$ (and more so in HF patients) and can be suppressed with further elevation of $\mathrm{PaO}_{2}$ beyond $100 \mathrm{~mm} \mathrm{Hg} .{ }^{19}$

\section{Effects of Acetazolamide on Gas Exchange, Exercise Performance, PB, and Sleep}

We found that when acetazolamide is given acutely and patients are studied before the development of any appreciable metabolic acidosis (Table 5) there is, compared with the basal test, a statistically nonsignificant increase in resting $\mathrm{V}_{\mathrm{E}}$ (Table 4) associated with an increase in $\mathrm{PaO}_{2}$ as well as $\mathrm{PaCO}_{2}$. These changes reflect the mild hyperventilatory stimulus of slight $\mathrm{CO}_{2}$ retention arising from partial red cell CA inhibition and complete vascular endothelial cell CA inhibition ${ }^{12,20}$ that occur with the transient high free drug levels reached with intravenous administration. The same pattern of gas exchange and increased $\mathrm{V}_{\mathrm{E}}$ relative to $\mathrm{CO}_{2}$ production $\left(\mathrm{V}_{\mathrm{E}} / \mathrm{VCO}_{2}\right)$ at rest is evident during exercise. Acute acetazolamide caused a slight reduction in peak $\mathrm{VO}_{2}$ and work load similar to that seen in healthy subjects, ${ }^{21}$ reflecting a possible limiting effect on exercise of a slightly higher ventilatory demand and a greater degree of $\mathrm{CO}_{2}$ retention and acidosis at the muscle (cardiac and skeletal) level that is not accurately reflected by arterial blood gas values. ${ }^{22}$

The trends noted above with acute acetazolamide on gas exchange and exercise performance were greater and reached statistical significance with the continued oral administration of the drug over the subsequent 24 hours. The patients had the expected fall in bicarbonate and lower arterial $\mathrm{pH}$ from renal loss of bicarbonate. ${ }^{12}$ In this situation of lower free drug levels with oral administration and a metabolic acidosis, $\mathrm{V}_{\mathrm{E}}$ was higher at rest and at all levels of exercise. As a result, arterial $\mathrm{PCO}_{2}$ was decreased and $\mathrm{PaO}_{2}$ was much higher. The lack of arterial $\mathrm{PCO}_{2}$ elevation compared with that observed with acute intravenous administration is consistent with less red cell CA inhibition and thus less impairment of pulmonary $\mathrm{CO}_{2}$ excretion. ${ }^{22}$ Despite better gas exchange, peak exercise was reduced, again likely owing to the acidosis and greater ventilatory demand causing a greater proportion of the cardiac output necessary to serve the respiratory muscles and diverting blood flow from the exercising locomotor muscles, ${ }^{23}$ as is observed in healthy humans given acetazolamide orally over 24 hours. $^{24}$

Acetazolamide acutely and after 24 hours of administration was effective in suppressing $\mathrm{PB}$ during exercise, but not as potently as $2 \%$ inhaled $\mathrm{CO}_{2}$. We chose to study $1 \%$ and $2 \%$ inhaled $\mathrm{CO}_{2}$ to recreate the slight degree of $\mathrm{CO}_{2}$ retention expected with acetazolamide, particularly with the acute intravenous dosing. In this respect we were successful, because the elevations in $\mathrm{PaCO}_{2}$ with $2 \%$ inhaled $\mathrm{CO}_{2}$ of $1.11 \mathrm{~mm} \mathrm{Hg}$ (Table 3) and with acute acetazolamide of $1.05 \mathrm{~mm} \mathrm{Hg}$ (Table 5) at roughly equivalent exercise levels were similar. However, this was not the case with prolonged acetazolamide, in which the $\mathrm{PaCO}_{2}$ was, in fact, lower and yet PB suppression was even greater with chronic acetazolamide than with acute acetazolamide. Although the slightly higher $\mathrm{PaCO}_{2}$ with acute dosing of acetazolamide and partial suppression of $\mathrm{PB}$ fits with a drug-induced widening of the eupneic-apneic $\mathrm{PCO}_{2}$ difference, the paradox of even greater $\mathrm{PB}$ suppression associated with lower $\mathrm{PaCO}_{2}$ with chronic acetazolamide requires explanation. The paradox was resolved by Nayakama et $\mathrm{al},{ }^{25}$ who showed that in sleeping dogs given acetazolamide and studied after a metabolic acidosis was established did widen the eupneic-apneic $\mathrm{PCO}_{2}$ difference. This was brought about by the increased tonic hyperventilation driving down the apneic $\mathrm{PCO}_{2}$ to a greater extent than eupneic $\mathrm{PCO}_{2}$ was lowered. This was also shown for almitrine, a nonhypoxic peripheral chemoreceptor stimulant, but not for hypoxia itself.

$\mathrm{CA}$ is present in many tissues, including the brain and chemoreceptors, ${ }^{12}$ and we must consider other actions by which acetazolamide might be effective in PB suppression both in exercise and during sleep. As mentioned above, PB may have as one of its contributors a mismatch or temporal dyssynchrony of inputs from the peripheral chemoreceptors (largely $\mathrm{O}_{2}$ sensing, but also $\mathrm{CO}_{2} / \mathrm{pH}$ sensing) and the central chemoreceptors (only $\mathrm{CO}_{2} / \mathrm{pH}$ sensing). One source of this mismatch (a delay in the time of transit of blood from the lungs to the chemoreceptors) could be differences in cardiac output with acetazolamide, but studies in animals and healthy humans show no reduction of cardiac output at any exercise level. ${ }^{26,27}$ The other manner in which the rate of afferent signaling might be altered relates to the effects of CA inhibition in the chemoreceptors themselves. $\mathrm{CA}$ inhibitors slow the rate at which the peripheral chemoreceptors respond to a change in $\mathrm{pO}_{2}$ and reduce the magnitude of the final response $\mathrm{s}^{20,28}$ as well as the rate of response to changes in $\mathrm{CO}_{2}{ }^{28}$ In similar fashion, the rate of response to $\mathrm{CO}_{2}$ in the central chemoreceptors also is slowed by acetazolamide. ${ }^{29}$ Slowing of these responses may be sufficient enough that in the event of a random increase or decrease in $\mathrm{V}_{\mathrm{E}}$ causing a change in $\mathrm{PaCO}_{2}$ and $\mathrm{PaO}_{2}$, the tendency of the respiratory controller to overreact and then underreact in response will be dampened or abolished, such as is the case in high-altitude $\mathrm{PB} .^{30,31}$ 
Our results showing PB suppression in exercise with acetazolamide differ somewhat from those of Fontana et $\mathrm{al},{ }^{14}$ who failed to find any effect, despite showing, as we did, reduction in PB and central apneas during sleep in these patients (see also Javaheri ${ }^{13}$ ) and reduction in maximal exercise capacity. They used a lower dose of prolonged acetazolamide ( $250 \mathrm{mg}$ every 12 hours for 4 days) in contrast to our higher dosing of $500 \mathrm{mg}$ every 8 hours over 24 hours. As a result, free drug levels and degree of tissue CA inhibition were considerably higher in our patients. ${ }^{15}$ Although no arterial blood gas measurements were taken by Fontana et al, ${ }^{14}$ we do not think the magnitude of metabolic acidosis was any different, because full renal CA inhibition is reached at very low doses $(1-2 \mathrm{mg} / \mathrm{kg})$ owing to drug concentration in the urine by renal tubular secretion. ${ }^{12}$ Instead, the difference in exercise PB responses must be dependent on greater and more critical inhibition of CA in the chemoreceptors and brain and thus require higher doses than the lower doses of acetazolamide that are effective in suppression of sleep breathing irregularities.

The heart contains several isoforms of CA at very low concentrations, ${ }^{32,33}$ but their roles remain uncertain given that even under the maximal demands of heavy exercise, there is no reduction of cardiac output ${ }^{26}$ or evidence of reduced myocardial contractility. ${ }^{34}$ Furthermore, with more than 5 decades of use in several chronic conditions, such as glaucoma, there have been no reports of adverse direct cardiac effects. In fact, more recent work suggests that acetazolamide may prevent and reverse cardiomyocyte hypertrophy ${ }^{33,35}$ by causing a very slight intracellular acidosis $^{36}$ that opposes the intracellular alkalizing hypertrophic stimulus initiated by alpha-adrenergic activation. ${ }^{33}$ This reassuring safety record would support a trial of acetazolamide in HF patients with PB and central sleep apnea. The benefits, particularly during sleep, of many hours of regular breathing might reduce neurosympathetic activation and perhaps alter the course of myocardial hypertrophic remodeling and the even more relevant risk of sudden cardiac death. $^{37}$

A few study limitations should be acknowledged. First, we strongly encouraged patients to perform a maximal effort; however, the test was self-ended by the patients when they felt that they had reached their maximal possible performance. In HF patients studied with CPET, peak exercise respiratory ratio $\left(\mathrm{VCO}_{2} / \mathrm{VO}_{2}\right)>1.1$ is used as an index of maximal or near-maximal exercise performance. However, with $\mathrm{PB}$, the respiratory ratio is cyclic with a wide variation, so that its value at peak exercise as an index of maximal metabolic effort has no meaning. Therefore, we can only rely on the patient's cooperation. Second, we studied the effects of acetazolamide for 2 days. The safety and the effects on respiratory parameters of acetazolamide with more chronic administration in chronic HF patients remain unknown. Our observation should not be used to suggest chronic treatment with acetazolamide in HF patients with exercise PB until a proper clinical trial is conducted. Third, we studied severe HF patients only in a stable clinical condition. The effects of acetazolamide administration in patients with an unstable clinical state or with relevant clinical comorbidities, such as lung disease or renal failure, is also unknown.

In conclusion, we have shown for the first time that both inhaled $\mathrm{CO}_{2}$ and acetazolamide favorably alter PB during exercise in HF patients, and we add further to the evidence of a benefit of acetazolamide during sleep. The mechanism of action of both inhaled $\mathrm{CO}_{2}$ and acetazolamide to reduce $\mathrm{PB}$ involves increasing the eupneic-apneic $\mathrm{PCO}_{2}$ difference so that any spontaneous variability of $\mathrm{V}_{\mathrm{E}}$ does not so easily drive arterial $\mathrm{PCO}_{2}$ below the apneic threshold. Furthermore, acetazolamide may also act to stabilize breathing by slowing the response dynamics of chemoreceptor signaling to the respiratory control center and so reduce the tendency of overresponse to small fluctuations in arterial $\mathrm{PCO}_{2}$ and $\mathrm{PO}_{2}$. Our findings and those of others suggest that whether breathing is stabilized or destabilized in HF patients is a complicated scenario dependent on the causes of background heightened ventilatory drive, the prevailing arterial and tissue partial $\mathrm{PCO}_{2}$ and $\mathrm{PO}_{2}$, and the speed at which changes in these gas values are sensed at sites of chemoreception, signaled, and then processed at the respiratory control center.

\section{Disclosures}

None.

\section{References}

1. Corra U, Pistono M, Mezzani A, Braghiroli A, Giordano A, Lanfranchi $\mathrm{P}$, et al. Sleep and exertional periodic breathing in chronic heart failure: prognostic importance and interdependence. Circulation 2006;113:44-50.

2. Sun XG, Hansen JE, Beshai JF, Wasserman K. Oscillatory breathing and exercise gas exchange abnormalities prognosticate early mortality and morbidity in heart failure. J Am Coll Cardiol 2010;55:1814-23.

3. Dhakal BP, Murphy RM, Lewis GD. Exercise oscillatory ventilation in heart failure. Trends Cardiovasc Med 2012;22:185-91.

4. Pinna GD, Maestri R, Mortara A, La Rovere MT, Fanfulla F, Sleight P. Periodic breathing in heart failure patients: testing the hypothesis of instability of the chemoreflex loop. J Appl Physiol (1985) 2000;89: 2147-57.

5. Ben-Dov I, Sietsema KE, Casaburi R, Wasserman K. Evidence that circulatory oscillations accompany ventilatory oscillations during exercise in patients with heart failure. Am Rev Respir Dis 1992;145(4 Pt 1):776-81.

6. Cherniack NS, Longobardo GS. Cheyne-stokes breathing. An instability in physiologic control. N Engl J Med 1973;288:952-7.

7. Agostoni P, Apostolo A, Albert RK. Mechanisms of periodic breathing during exercise in patients with chronic heart failure. Chest 2008;133: $197-203$.

8. Steens RD, Millar TW, Su X, Biberdorf D, Buckle P, Ahmed M, Kryger MH. Effect of inhaled $3 \% \mathrm{CO}_{2}$ on Cheyne-Stokes respiration in congestive heart failure. Sleep 1994;17:61-8.

9. Lorenzi-Filho G, Rankin F, Bies I, Douglas Bradley T. Effects of inhaled carbon dioxide and oxygen on Cheyne-Stokes respiration in patients with heart failure. Am J Respir Crit Care Med 1999;159(5 Pt 1):1490-8. 
10. Giannoni A, Baruah R, Willson K, Mebrate Y, Mayet J, Emdin M, et al. Real-time dynamic carbon dioxide administration: a novel treatment strategy for stabilization of periodic breathing with potential application to central sleep apnea. J Am Coll Cardiol 2010;56: 1832-7.

11. Hackett PH, Roach RC, Harrison GL, Schoene RB, Mills WJ Jr. Respiratory stimulants and sleep periodic breathing at high altitude. Almitrine versus acetazolamide. Am Rev Respir Dis 1987;135:896-8.

12. Swenson ER. Carbonic anhydrase inhibitors and ventilation: A complex interplay of stimulation and suppression. Eur Respir J 1998;12: 1242-7.

13. Javaheri S. Acetazolamide improves central sleep apnea in heart failure: a double-blind, prospective study. Am J Respir Crit Care Med 2006; 173:234-7.

14. Fontana M, Emdin M, Giannoni A, Iudice G, Baruah R, Passino C. Effect of acetazolamide on chemosensitivity, cheyne-stokes respiration, and response to effort in patients with heart failure. Am J Cardiol 2011;107:1675-80.

15. Teppema LJ, Dahan A. Acetazolamide and breathing. Does a clinical dose alter peripheral and central $\mathrm{CO}_{2}$ sensitivity? Am J Respir Crit Care Med 1999;160(5 Pt 1):1592-7.

16. Corra U, Giordano A, Bosimini E, Mezzani A, Piepoli M, Coats AJ, Giannuzzi P. Oscillatory ventilation during exercise in patients with chronic heart failure: clinical correlates and prognostic implications. Chest 2002;121:1572-80.

17. Tkacova R, Niroumand M, Lorenzi-Filho G, Bradley TD. Overnight shift from obstructive to central apneas in patients with heart failure: role of $\mathrm{PCO}_{2}$ and circulatory delay. Circulation 2001;103:238-43.

18. Swenson ER, Robertson HT, Hlastala MP. Effects of inspired carbon dioxide on ventilation-perfusion matching in normoxia, hypoxia, and hyperoxia. Am J Respir Crit Care Med 1994;149:1563-9.

19. Schultz HD, Marcus NJ. Heart failure and carotid body chemoreception. Adv Exp Med Bio 2012:387-95.

20. Swenson ER, Hughes JM. Effects of acute and chronic acetazolamide on resting ventilation and ventilatory responses in men. J Appl Physiol 1993:74:230-7.

21. Kowalchuk JM, Heigenhauser GJ, Sutton JR, Jones NL. Effect of acetazolamide on gas exchange and acid-base control after maximal exercise. J Appl Physiol 1992;72:278-87.

22. Swenson ER, Maren TH. A quantitative analysis of $\mathrm{CO}_{2}$ transport at rest and during maximal exercise. Respir Physiol 1978;35:129-59.

23. Harms CA, Wetter TJ, McClaran SR, Pegelow DF, Nickele GA, Nelson WB, et al. Effects of respiratory muscle work on cardiac output and its distribution during maximal exercise. J Appl Physiol 1998;85: 609-18.

24. Schoene RB, Bates PW, Larson EB, Pierson DJ. Effect of acetazolamide on normoxic and hypoxic exercise in humans at sea level. J Appl Physiol 1983;55:1772-6.

25. Nakayama H, Smith CA, Rodman JR, Skatrud JB, Dempsey JA. Effect of ventilatory drive on carbon dioxide sensitivity below eupnea during sleep. Am J Respir Crit Care Med 2002;165:1251-60.

26. Jonk AM, van den Berg IP, Olfert IM, Wray DW, Arai T, Hopkins SR, Wagner PD. Effect of acetazolamide on pulmonary and muscle gas exchange during normoxic and hypoxic exercise. J Physiol 2007;579(Pt 3):909-21.

27. Vengust M, Staempfli H, Swenson ER, et al. Acetazolamide attenuates transvascular fluid flux in equine lungs during intense exercise. J Physiol 2013;591(Pt 18):4499-513.

28. Iturriaga R, Mokashi A, Lahiri S. Dynamics of carotid body responses in vitro in the presence of $\mathrm{CO}_{2}-\mathrm{HCO}_{3}{ }^{-}$: role of carbonic anhydrase. $\mathrm{J}$ Appl Physiol 1993;75:1587-94.

29. Coates EL, Li AH, Nattie EE. Acetazolamide on the ventral medulla of the cat increases phrenic output and delays the ventilatory response to $\mathrm{CO}_{2}$. J Physiol 1991;441:433-51.

30. Berssenbrugge A, Dempsey J, Iber C, Skatrud J, Wilson P. Mechanisms of hypoxia-induced periodic breathing during sleep in humans. J Physiol 1983;343:507-24.

31. Swenson ER, Teppema LJ. Prevention of acute mountain sickness by acetazolamide: as yet an unfinished story. J Appl Physiol 2007;102: $1305-7$

32. Swenson ER. Carbonic anhydrase and the heart. Cardiologia 1997;42: 453-62.

33. Alvarez BV, Johnson DE, Sowah D, Soliman D, Light PE, Xia Y, et al. Carbonic anhydrase inhibition prevents and reverts cardiomyocyte hypertrophy. J Physiol 2007;579(Pt 1):127-45.

34. Geers C, Gros G. Contractile function of papillary muscles with carbonic anhydrase inhibitors. Life Sci 1995;57:591-7.

35. Brown BF, Quon A, Dyck JR, Casey JR. Carbonic anhydrase II promotes cardiomyocyte hypertrophy. Can J Physiol Pharmacol 2012; 90:1599-610.

36. Vaughan-Jones RD, Spitzer KW, Swietach P. Intracellular ph regulation in heart. J Mol Cell Cardiol 2009;46:318-31.

37. Guazzi M, Raimondo R, Vicenzi M, Arena R, Proserpio C, Sarzi Braga S, Pedretti R. Exercise oscillatory ventilation may predict sudden cardiac death in heart failure patients. J Am Coll Cardiol 2007;50: 299-308. 